\title{
Study on the Synthesis, Characterization of p-CuSCN/n-Si Heterojunction
}

\author{
Xiong Chao ${ }^{*}, 1,2$, Chen Lei ${ }^{1}$ and Yuan Hongchun ${ }^{1}$ \\ ${ }^{1}$ School of Photoelectric Engineering, Changzhou Institute of Technology, Changzhou, Jiangsu 213002, China \\ ${ }^{2}$ School of Electronic and Information Engineering, South China University of Technology, Guangzhou, Guangdong \\ 510641, China
}

\begin{abstract}
The p-CuSCN/n-Si heterojunction is fabricated by depositing CuSCN films on n-Si (111) films substrate using successive ionic layer adsorption and reaction (SULAR). CuSCN films show $\beta$-phase structure by virtue of X-ray diffraction (XRD) spectroscopy. $\mathrm{ZnO} / \mathrm{CuSCN}$ heterojunctions exhibit good diode characteristics and photovoltaic effects with illumination form its current-voltage (I-V) measurements. The linear relationship of $1 / \mathrm{C}^{2}$ versus voltage curve implies that the built-in potential $\mathrm{V}_{\mathrm{bi}}$ and the conduction band offset of the heterojunctions were found to be $2.1 \mathrm{eV}$ and $1.5 \mathrm{eV}$, respectively. The forward conduction is determined by trap-assisted space charge limited current mechanism. At forward bias voltages, the electronic potential barrier is larger than holes in the p-CuSCN/n-Si heterojunction interface. In this voltage area, a single carrier injuction is induced and the main current of $\mathrm{p}-\mathrm{CuSCN} / \mathrm{n}-\mathrm{Si}$ heterojunction is hole current. In addition, a band diagram of $\mathrm{ZnO} / \mathrm{CuSCN}$ heterojunctions is also proposed to explain the transport mechanism. This heterojunction diode can be well used to light emission devices and photovoltaic devices.
\end{abstract}

Keywords: Heterojunction diode, p-CuSCN/n-Si, the current transport mechanism.

\section{INTRODUCTION}

Wide gap semiconductor films/Si heterojunction structures have been intensively studied these days for various applications including solar cells, light emission devices, UV detectors, and display technology [1-3]. Interface states of the heterojunction is difficult to overcome. Among all of these p-type semiconductors, $\mathrm{CuSCN}$ of p-type plays an role in the wide gap emitter material, having a band gap of $3.6 \mathrm{eV}$, which has been used in extremely thin absorber solar cells (ETAs) as a p-type hole conducting material [4-8]. Additionally, as an economically viable optoelectronic device material and preparation of $\mathrm{CuSCN}$ films at low temperature, p-CuSCN films have drawn intensive attention [7-11]. Literatures [6] and [7] focused on filling of $\mathrm{CuSCN}$ on $\mathrm{ZnO}$ rod arrays by the electrodeposition method to form $\mathrm{p}-\mathrm{CuSCN} / \mathrm{n}-\mathrm{ZnO}$ rod array interpenetrating heterojunctions. Aé et. al. [8] reported a hybrid flexible vertical nanoscale diodes, which formed by n-type $\mathrm{ZnO}$ and p-type CuSCN embedded in polymer foil, by using electrochemical deposition technique. In Ref. [9], they presented a light-emitting diodes consisting of $\mathrm{n}-\mathrm{ZnO}$ nanorods and $\mathrm{p}-\mathrm{CuSCN}$ prepared by electrochemical method. However, there are few reports to research for $\mathrm{p}$ $\mathrm{CuSCN} / \mathrm{n}-\mathrm{Si}$ heterojunctions recently.

In this paper, $\mathrm{p}-\mathrm{CuSCN} / \mathrm{n}-\mathrm{Si}$ heterojunctions are fabricated by using simple solution method at low

*Address correspondence to this author at the School of Photoelectric Engineering, Changzhou Institute of Technology, Changzhou, Jiangsu 213002, China; Tel:086+13656142469; Fax: :086+51985212952;

E-mail:xiongchaoxc88@163.com temperature. CuSCN thin films are deposited on $\mathrm{n}-\mathrm{Si}$ substrate by SILAR. This method fabricating $\mathrm{p}-\mathrm{CuSCN} / \mathrm{n}-\mathrm{Si}$ heterojunctions has not been seen in previous reports. The current transport properties of the heterojunctions are also investigated by means of current-voltage measurements and capacitance voltage method.

\section{EXPERIMENT}

\subsection{Deposition of CuSCN Films Using SILAR}

The deposition of $\mathrm{CuSCN}$ thin films onto $\mathrm{n}$-Si substrate was taken at room temperature by SILAR method. Here, we used $\mathrm{CuSO}_{4} \cdot 5 \mathrm{H}_{2} \mathrm{O}(0.02 \mathrm{~mol} / \mathrm{L})$ solution complexed by $\mathrm{Na}_{2} \mathrm{~S}_{2} \mathrm{O}_{3}(0.08 \mathrm{~mol} / \mathrm{L})$ as a cationic precursor. The release of $\mathrm{Cu}$ (I) ions is possible via the following reaction

$\left[\mathrm{Cu}\left(\mathrm{S}_{2} \mathrm{O}_{3}\right)\right]^{-}=\mathrm{Cu}^{+}+\mathrm{S}_{2} \mathrm{O}_{3}^{2-}$

which acts as a source of cations. The ratio of $\mathrm{CuSO}_{4}: \mathrm{Na}_{2} \mathrm{~S}_{2} \mathrm{O}_{3}$ is $5: 2$. Aqueous solution of $\mathrm{KSCN}$ (0.025 $\mathrm{mol} / \mathrm{dm} 3$ ) was used as an anionic precursor. The $\mathrm{n}-\mathrm{Si}$ substrate was immersed in a cationic precursor for $10 \mathrm{~s}$. Copper ions were absorbed on the surface of the substrate and the un-absorbed ions were removed by rinsing the $\mathrm{n}-\mathrm{Si}$ substrate in de-ionized water (resistivity $\sim 18 \mathrm{M} \Omega \mathrm{cm}$ ) for $5 \mathrm{~s}$. For the reaction with SCN - ions, the substrate was immersed in an anionic precursor for 20 s.

$\left[\mathrm{Cu}\left(\mathrm{S}_{2} \mathrm{O}_{3}\right)\right]^{-}+\mathrm{SCN}^{-}=\mathrm{CuSCN} \downarrow+\mathrm{S}_{2} \mathrm{O}_{3}^{2-}$

The powdery material or loosely bounded ions were removed by rinsing the substrate in de-ionized water for $5 \mathrm{~s}$. Thus, we complete one SILAR cycle, and this SILAR cycle need attain 100 . 


\subsection{Characterization and Measurements}

The samples were frozen in liquid nitrogen and sliced by freezing slicer. The phase composition of the samples was characterized by X-ray powder diffraction (XRD, RINT$2100 V$, Rigaku, $\mathrm{Cu} \mathrm{K} \alpha$ ). In Fig. (1), we present wide gap diode of a structure "indium doped tin oxide (ITO) glass/p$\mathrm{CuSCN} / \mathrm{n}-\mathrm{Si}$ ". The ITO/p-CuSCN contact was obtained simply by pressing a commercial ITO glass on a deposited pCuSCN films. Current-voltage (I-V) characteristics between two ITO glasses were measured using an Agilent sourcemeter (model 4156C). Capacitance-voltage (C-V) characteristics were measured using an Agilent LCR meter (model 4824A). Electrical resistivity of the films was measured by a four-point method (4 PROBES TECH China RTS-9).

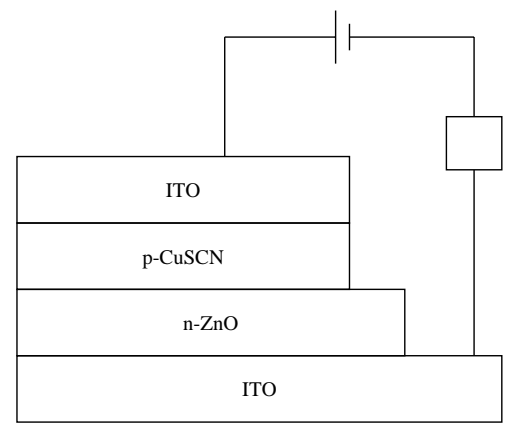

Fig. (1). Schematic structure of fabricated n-Si/p-CuSCN /ITO heterojunction.

\section{RESULTS AND DISCUSSIONS}

\subsection{Structural Characterization}

Fig. (2) shows the XRD spectra of the as-grown CuSCN films on $\mathrm{n}$-Si. The observed inter-planer distance "d" is compared with JCPDS data which is in good agreement with the standard "d" values. Analyses of XRD data reveal peaks corresponding to (111) and (101) planes of the Si crystal structure, and different peaks of $\beta$-CuSCN corresponding to planes (003), (101), (006), (104), (015), (110), (113) and (021), are identified as wurtzite structure. The preferential orientation of the $\beta$-CuSCN grains is also observed along the (003) axis aligning with the growth direction. The presence of a number of peaks in XRD pattern is the indication of polycrystalline nature of the $\mathrm{CuSCN}$.

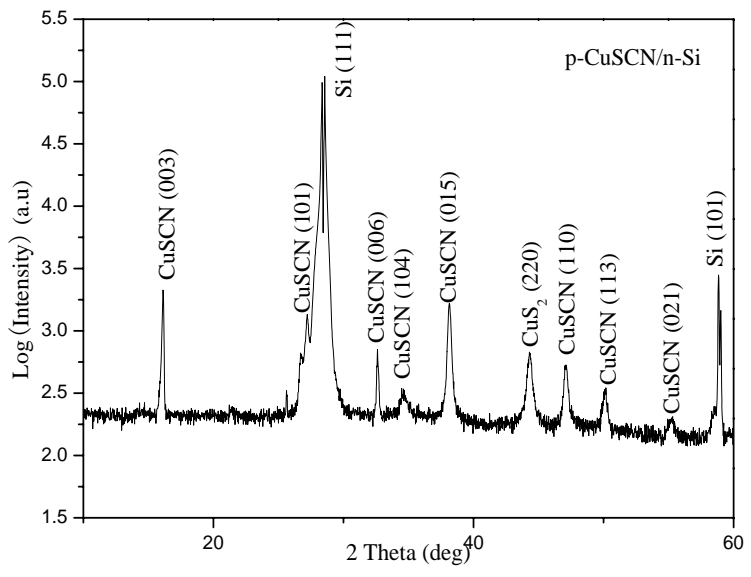

Fig. (2). X-ray diffraction spectra of p-CuSCN films on n-Si.

\subsection{Electrical Characteristics}

The resistivities of ITO and p-CuSCN are $63 \Omega / \square$ and $230 \Omega / \square$, respectively. The electrical conductivity of p$\mathrm{CuSCN}$ as well as commercial ITO glass is very high, and the obtained current was stable with time, indicating that a reasonable electrical contact is formed at the ITO/p-CuSCN interface. The I-V characteristic of the heterojunction in Fig. (3) exhibits a good photoelectric effect and rectifying behavior with a IF/IR $\sim 6$ at $5 \mathrm{~V}$, indicating formation of a diode (IF and IR stand for the forward and reverse currents, respectively). The turn on voltage can be observed and is about 1.0V from Fig. (3). Under light irradiation, when forward current increases, the reverse current hardly changes.

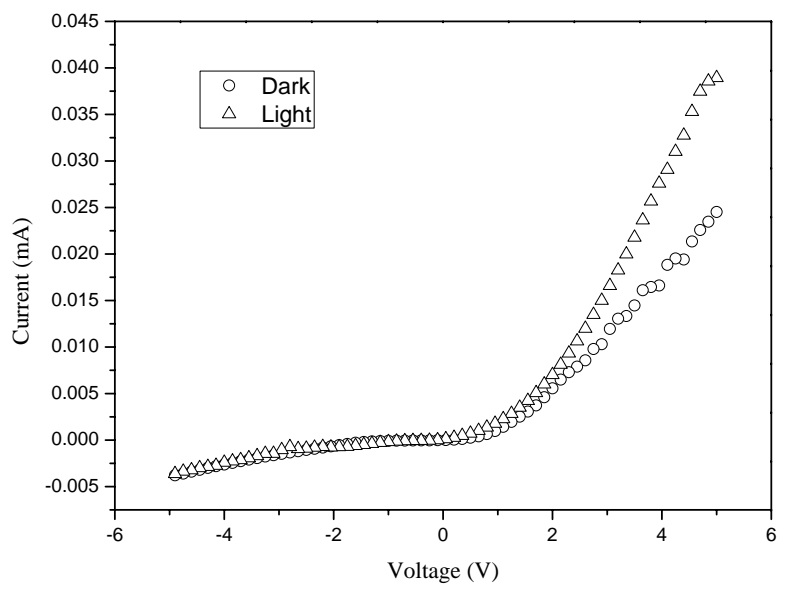

Fig. (3). I-V curve for the p-CuSCN/n-Si heterojunction with illumination and no illumination.

The $1 / \mathrm{C}^{2}$ versus voltage curve of the $\mathrm{p}-\mathrm{CuSCN} / \mathrm{n}-\mathrm{Si}$ heterojunction diode is shown in Fig. (4).

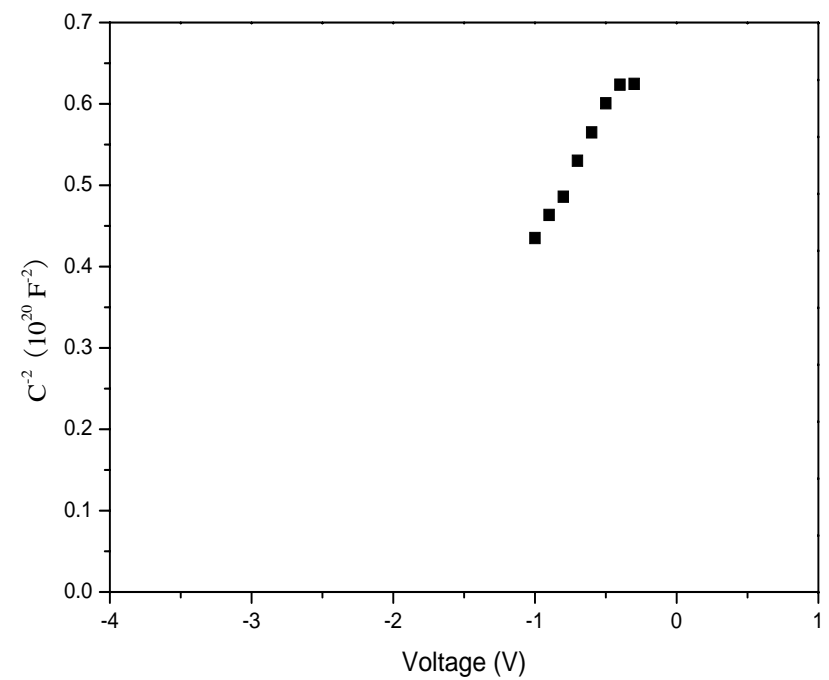

Fig. (4). The $1 / \mathrm{C}^{2}$ versus voltage curve of the $\mathrm{p}-\mathrm{CuSCN} / \mathrm{n}-\mathrm{Si}$ heterojunction diode measured at $500 \mathrm{kHz}$.

If the influence of the interface states is ignored at the p$\mathrm{CuSCN} / \mathrm{n}$-Si heterojunction interface, the relationship of the capacitance and the applied voltage is expressed as 


$$
. C^{2}=\frac{q N_{\mathrm{A}} N_{\mathrm{D}} \varepsilon_{1} \varepsilon_{2}}{2\left(N_{\mathrm{A}} \varepsilon_{1}+N_{\mathrm{D}} \varepsilon_{2}\right)} \frac{1}{\left(V_{\mathrm{D}}-V\right)} .
$$

where $N_{A}$ is the donor concentration of the p-CuSCN, and $N_{\mathrm{D}}$ is the acceptor concentration of n-Si, respectively. $N_{\mathrm{A}}$ and $N_{\mathrm{D}}$ can also be viewed as net effective space charge density in the space charge region (assuming impurities completely ionized). $\varepsilon_{1}, \varepsilon_{2}$ denote mediated dielectric constant of $\mathrm{Si}$ and $\mathrm{CuSCN}$, respectively. V stands for bias voltage application, $V_{\mathrm{D}}$ is sized for the built-in potential barrier.

Fig. (4) shows the linear relationship of $1 / \mathrm{C}^{2}$ versus voltage curve of the $\mathrm{p}-\mathrm{CuSCN} / \mathrm{n}-\mathrm{Si}$ heterojunction in the case of ignoring interface state. It is found that the built-in potential $\mathrm{V}_{\mathrm{bi}}$ of the heterojunction is $2.1 \mathrm{eV}$.

\subsection{Carrier Transport Mechanism}

In Fig. (5), we give the dark current as a function of junction-voltage in forward bias. At forward voltage, the I-V characteristic was deviated from the ideal thermionic emission and behaved as $I \sim V^{2}$ relation, which was attributed to the space-charge limited current (SCLC) conduction [1215]. This SCLC mechanism is a normal phenomenon in the wide band gap semiconductors due to single-carrier injection $[14,15]$.

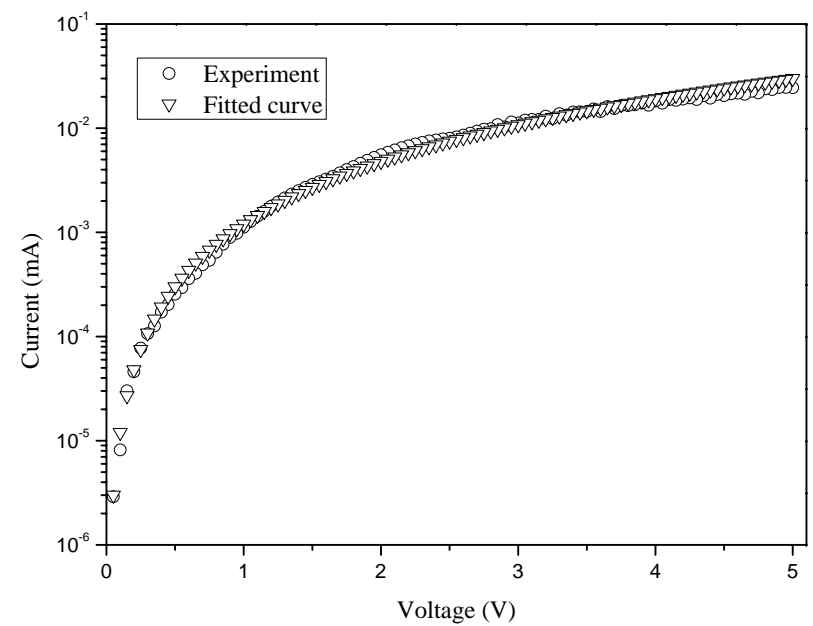

Fig. (5). The I-V curve for the p-CuSCN/n-Si heterojunction in forward bias.

Fig. (6) shows the theoretically expected equilibrium energy band diagram of the $\mathrm{p}-\mathrm{CuSCN} / \mathrm{n}-\mathrm{Si}$ heterojunction according to the Anderson model. Suppose that the interface states can be neglected and the Fermi level in the Si and $\mathrm{CuSCN}$ lies at the Si conduction band edge and $\mathrm{CuSCN}$ valence band edge, respectively. The model shows the maximum built-in potential $\mathrm{V}_{\mathrm{bi}}$ of the heterojunction is 2.1 $\mathrm{eV}$, which can be seen from the $\mathrm{C}-\mathrm{V}$ measurement results of Fig. (4). As can be seen from Fig. (6), it can be approximated estimation that the conduction band offset $\left(\triangle E_{\mathrm{C}}\right)$ and value band offset $\left(\triangle E_{\mathrm{V}}\right)$ of $\mathrm{p}$-CuSCN/ $\mathrm{n}$-Si heterojunction are $1.5 \mathrm{eV}$ and $0.98 \mathrm{eV}$, respectively.

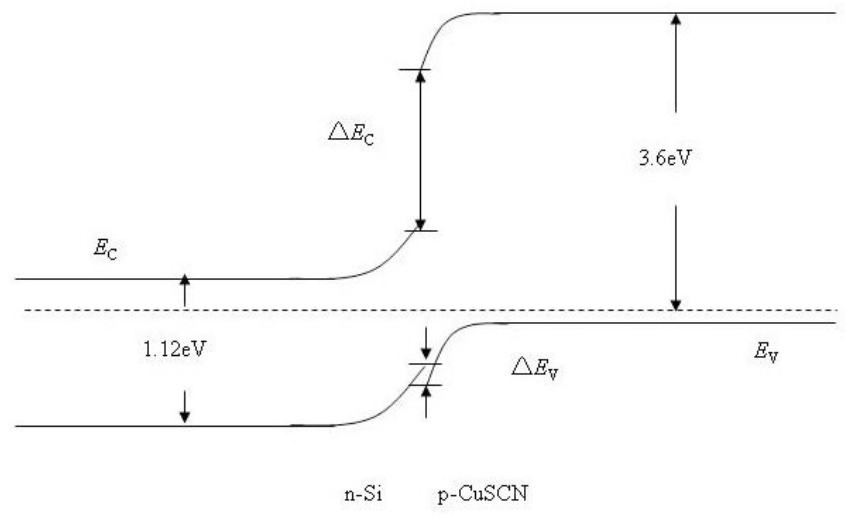

Fig. (6). The energy band diagram of $\mathrm{n}-\mathrm{Si} / \mathrm{p}-\mathrm{CuSCN}$ heterojunction.

From Fig. (6), we know that the $\Delta E_{\mathrm{C}}$ and $\Delta E_{\mathrm{V}}$ for this heterojunction are very large. The potential barrier for electrons transport from the bottom of conduction band in n$\mathrm{Si}$ to the bottom of conduction band in $\mathrm{p}-\mathrm{CuSCN}$ and the holes transport from the top of value band in $\mathrm{p}-\mathrm{CuSCN}$ to the top of value band in n-Si is very large, so the difficulties for transport of electrons and holes in forward bias is increased. Since the difference between $\Delta E_{\mathrm{C}}$ and $\Delta E_{\mathrm{V}}$, the energetic barrier is much lower for holes than electrons. In the region II, the current is dominated by holes, which agrees with the observed turn on voltage $(1.0 \mathrm{~V})$.

\section{CONCLUSIONS}

In summary, $\mathrm{p}-\mathrm{CuSCN} / \mathrm{n}-\mathrm{Si}$ heterojunction diode is prepared at a low cost by chemical method, and shows a good photoelectric effect and rectifying behavior with an IF/IR $\sim 6$ at $5 \mathrm{~V}$. The prepared $\beta$-CuSCN film is polycrystalline nature. The built-in potential is $2.1 \mathrm{eV}$ from $\mathrm{C}-\mathrm{V}$ characteristic. The conduction band offset and value band offset of $\mathrm{p}-\mathrm{CuSCN} / \mathrm{n}-\mathrm{Si}$ heterojunction are $1.5 \mathrm{eV}$ and $0.98 \mathrm{eV}$, respectively. The current transport mechanism is also dominated by the SCLC at forward bias voltages. This heterojunction diode can be well used for photoelectric devices and detectors.

\section{ABOUT THE AUTHORS}

First Author Xiong Chao was born in Hubei province of China in 1982, and graduated from South China University of Technology in June 2011, and received his Ph.D. degree. He began work in Changzhou Institute of Technology in July 2011. Over the years, he mainly engaged in the development and application research of new optoelectronic devices, thinfilm solar cells. 10 papers published in academic journals, the vast majority of SCI, EI indexed.

Second Author Chen lei was born in Anhui province of China in 1982, and graduated from University of Science and Technology of China in June 2010, and received his $\mathrm{Ph} . \mathrm{D}$. degree. He began work in Changzhou Institute of Technology in July 2010. Over the years, he mainly engaged in the development and application research of new optoelectronic devices. 8 papers published in academic journals, the vast majority of SCI indexed.

Third Author Yuan Hongchun was born in Jiangsu province of China in 1976, and graduated from Shanghai 
Jiaotong University in June 2011, and received his Ph.D. degree. He began work in Changzhou Institute of Technology in July 2011. Over the years, he mainly engaged in the development and application research of thin-film solar cells. 20 papers published in academic journals, the vast majority of SCI indexed.

\section{CONFLICT OF INTEREST}

The authors confirm that this article content has no conflict of interest.

\section{ACKNOWLEDGEMENTS}

The work was financially supported by the Natural Science Foundation of Changzhou Institute of Technology, China (No. YN1105), the Science and Technique Foundation of Changzhou, China (No. CJ20120001), the Natural Science Foundation of the Jiangsu Higher Education Institutions of China (No.12KJD510001), as well as the Special Fund for Theoretical Physics from the National Natural Science Foundation of China (No.11247323).

\section{REFERENCES}

[1] Jeong IS, Kim JH, Im S. Ultraviolet-enhanced photodiode employing n-ZnO/p-Si structure. Appl Phys Lett 2003; 83: 2946.

[2] Zhang TC, Guo Y, Mei ZX, Gu CZ, Du XL. Visible-blind ultraviolet photodetector based on double heterojunction of $\mathrm{n}$ ZnO/insulator-MgO/p-Si. Appl Phys Lett 2009; 94: 113508.

[3] Mridha S, Basak D. Ultraviolet and visible photoresponse properties of $\mathrm{n}-\mathrm{ZnO} / \mathrm{p}-\mathrm{Si}$ heterojunction. J Appl Phys 2007; 101: 083102.

[4] Dittrich T, Kieven D, Rusu M, et al. Current-voltage characteristics and transport mechanism of solar cells based on $\mathrm{ZnO}$ nanorods/In2S3/CuSCN. Appl Phys Lett 2008; 93: 053113.
[5] Tena-Zaera R, Katty A, Bastide S, Lévy-Clément C, O'Regan B, Muñoz-Sanjosé $\mathrm{V}$. ZnO/CdTe/CuSCN, a promising heterostructure to act as inorganic eta-solar cell. Thin Solid Films 2005; 483: 3727.

[6] Yong $\mathrm{Ni}$, Zhengguo Jin, Ke Yu, Yanan Fu, Tongjun Liu, Tao Wang. Electrochemical deposition characteristics of p-CuSCN on n-ZnO rod arrays films. Electrochim Acta 2008; 53: 6048-54.

[7] Weibing W, Shougang C, Changhong Y, Guangda H, Haitao W. Electrochemically superfilling of n-type $\mathrm{ZnO}$ nanorod arrays with p-type CuSCN semiconductor. Electrochem Commun 2009; 11: 1736-9.

[8] Aé L, Chen J, Lux-Steiner MC. Hybrid flexible vertical nanoscale diodes prepared at low temperature in large area. Nanotechnology 2008; 19: 475201.

[9] Qiaobao Z, Honghui G, Zengfang F, Lingling L, Jianzhang Z, Zhonghua L. n-ZnO nanorods/p-CuSCN heterojunction lightemitting diodes fabricated by electrochemical method. Electrochim Acta 2010; 55: 4889-94.

[10] Sankapal BR, Goncalves E, Ennaoui A, Lux-Steiner MC Wide band gap p-type windows by CBD and SILAR methods. Thin Solid Films 2004; 451-452: 128-32.

[11] Chu DW, Hamada T, Kato K, Masuda Y. Growth and electrical properties of $\mathrm{ZnO}$ films prepared by chemical bath deposition method. Phys Status Solid A 2009; 206: 718-23.

[12] Jeong IS, Kim JH, Park H. n- ZnO/p-Si UV photodetectors employing AlOx films for antireflection. Thin Solid Films 2004; 447-448: 111-4.

[12] Miyake A, Kominami H, Tatsuoka H. Luminescent properties of $\mathrm{ZnO}$ thin films grown epitaxially on $\mathrm{Si}$ substrate. J Cryst Growth 2000; 214/215: 294-8.

[13] Dutta M, Basak D. p-ZnO/n-Si heterojunction: Sol-gel fabrication, photoresponse properties, and transport mechanism. Appl Phys Lett 2008; 92: 212112

[14] Liu S, Chen T, Jiang Y. The effect of postannealing on the electrical properties of well-aligned $\mathrm{n}-\mathrm{ZnO}$ nanorods $/ \mathrm{p}-\mathrm{Si}$ heterojunction. J Appl Phys 2009; 105: 114504

[15] Iwata K, Fons P, Niki S. ZnO growth on Si by radical source MBE. J Cryst Growth 2000; 214/215: 50-4. 